\title{
Detection of Proteins Synthesized during the Establishment of Lysogeny with Phage P22
}

\author{
LARRY W. COHEN ${ }^{2}$ AND MYRON LEVINE \\ Department of Human Genetics and the Lawrence D. Buhl Research Cenler for Human Genetics, University \\ of Michigan, Ann Arbor \\ Accepted October 7, 1965
}

\begin{abstract}
A method is described which utilizes pulse labeling with $\mathrm{S}^{35}$, starch gel electrophoresis, and autoradiography to detect the synthesis of proteins at various times af ter infection of Salmonella typhimurium with phage P22. The system was developed especially to study proteins involved in lysogeny. A comparison was made of various infections. These involve the wild-type phage $\left(c^{+}\right)$under conditions producing a high frequency of lysogeny; elear mutants, $c_{1}$ and $c_{z}$, each producing $100 \%$ lysis; and infection with temperature-sensitive mutants unable to make viable phage at $37^{\circ}$. The $c^{+}, c_{1}$, and $c_{2}$ phage infections caused the appearance of four new protein bands at about the 4 th minute after infection. The synthesis of these bands persisted throughout the latent period in the infections leading to phage production and lysis (with phages $c_{1}$ and $c_{2}$ ). In the $c^{+}$infection, synthesis continued through the 8 th minute, following which the rate decreased until approximately the 20th minute, when synthesis of the bands was no longer detectable. In infection with a particular temperature-sensitive phage mutant, three of the four bands were missing but a new band was ubserved. The evidence suggests that the proteins whose synthesis was observed are associated with phage production and are phage-specified proteins. The implications of these findings with respect to control phenomena in lysogeny are discussed.
\end{abstract}

\section{INTRODUCTION}

Very little is known about the rolc of specific proteins in establishing and maintaining the lysogenic state and in the synthesis of temperate phages in general. A method for the detection of proteins synthesized following infection of Salmonella typhimurium with the temperate phage P22 has been developed. The method utilizes pulse-labeling with $\mathrm{S}^{35}$, starch gel electrophoresis, and autoradiography. The synthesis of four phage-sperific protein bands has been detected and studied in infections with wild type and mutant phage.

1 Supported by PHS grant GM-09252-02.

${ }^{2}$ PHS Post-doctoral Research Fellow (1-F2. GM-15074-02). Present address: Department of Biological Sciences, Douglass College, Rutgersthe State University, New Brunswick, New Jersey.

\section{MATERIALS AND METHODS}

Bacteriophage strains. Purified stocks of wild-type $\left(c^{+}\right)$phage P22 and two complementing clear mutants, $c_{1}{ }^{7}$ and $c_{2}{ }^{5}$, were used in these experiments. A description of these mutants and their positions on the phage linkage map has been given (Levine, 1957; Levine and Curtiss, 1961). Five mutually complementing temperature-sensitive mutants were isolated following $N$-methyl$N^{\prime}$-nitro- $N$-nitrosoguanidinemutagenesis. Independently derived $c_{2}$ derivatives of each mutant were utilized in some of the experiments (Levine, unpublished). A description of the temperature-sensitive mutants will be presented in a later publication.

Bacterial strains. Salmonella typhimurium strain LT-2 was used in all infections. A galmutant was used as background for plating.

Media. (1) Low sulfur M9 medium (LSM): $\mathrm{KH}_{2} \mathrm{PO}_{4}, 0.022 M ; \mathrm{Na}_{2} \mathrm{HPO}_{4}, 0.042 \quad M$; 
$\mathrm{NH}_{4} \mathrm{Cl}, 0.018 M ; \mathrm{MgCl}_{2}, 2.5 \times 10^{-3} M$; $\mathrm{NaCl}, 8.5 \times 10^{-3} \mathrm{M} ; \mathrm{MgSO}_{4}, 3 \times 10^{-4} \mathrm{M}$; glucose, $0.2 \%$. (2) Minus sulfur M9 medium (MSM): the same as ISM but lacking $\mathrm{MgSO}_{4}$. (3) Buffered saline (BS): NaCl, $0.145 M ; \mathrm{KH}_{2} \mathrm{PO}_{4}, 0.022 M ; \mathrm{Na}_{2} \mathrm{HPO}_{4}$, $0.042 \mathrm{M} ; \mathrm{pH} 7$.

Growth and infection of bacterial cells and pulse labeling with $S^{35}$. Overnight cultures of bacteria in LSM were diluted $1: 3$ in fresh LSM and aerated at $37^{\circ}$. When the culture had grown to an optical density of 0.90 at a wavelength of $650 \mathrm{~m} \mu$ a sample was diluted 10-fold in MSMI and again grown with aeration to an $\mathrm{OD}_{650}$ of 0.40 (approximatcly $2.7 \times 10^{8}$ cells $/ \mathrm{ml}$ ). Phage was then added to a multiplicity of infection of 20 . At various times thereafter, $20-\mathrm{ml}$ aliquots were transferred to prewarmed centrifuge tubes containing $150 \mu \mathrm{C}$ of carrier-free $\mathrm{S}^{35} \mathrm{O}_{4}^{--}$ (Nuclear Chicago). After 3 minutes of exposure to the isotope, labeling was stopped by chilling with ice and by addition of $2 \mathrm{ml}$ $0.11 M \mathrm{NaCN}$. The cells were washed twice with $20 \mathrm{ml}$ of BS by centrifugation and resuspended in a final volume of $1 \mathrm{ml} \mathrm{BS}$.

Preparation of cell-free extracts. The concentrated cell suspensions were transferred to 5 -ml celluloid tubes in ice water and the cells were disrupted by sonication. Four 15second ultrasonic pulses were administered, separated by 1-minute intervals to permit cooling. Cell debris was removed by centrifugation at 35,000 $g$ for 10 minutes. The slightly cloudy supernatant fluid was used for electrophoresis.

Separation of soluble protein by starch gel electrophoresis. Starch gels were prepared according to the method of Smithies (1959). Forty-five grams of starch (Connaught Medical Research Laboratories) was suspended in $350 \mathrm{ml}$ buffer (0.045 $M$ Tris, $0.025 M$ boric acid, $0.001 M$ EDTA; $\mathrm{pH} 8.6$ ) and slowly heated in a 1-l heavy-walled Pyrex vacuum flask until the suspension became viscous and somewhat clear. The use of Plexiglas molds producing a gel with six wells enabled the simultaneous comparison of six extracts.

After the wells were filled with cell extracts, they were covered with melted petrolatum. The entire gel was then enclosed in
Saran Wrap to minimize surface evaporation and was subjected to vertical electrophoresis. The proteins of interest migrated toward the anode. Electrophoresis was carried out for 16 hours at 550 volts $(18 \mathrm{v} / \mathrm{cm})$ and with a current flow of $6 \mathrm{ma} / \mathrm{gel}$. The bridge buffer $(\mathrm{pH}=8.6)$ contained $0.11 M$ Tris, $0.063 M$ boric acid, and $0.0025 M$ EDTA. Bovine serum albumin and a crystal of Amido Schwartz stain were placed in one of the wells to provide a visual marker. Electrophoresis was considered complete when the stained albumin had migrated 3.5 inches from the well. The gels were sliced lengthwise into threc laycrs by means of two appropriately spaced taut wires. Finer autoradiographic resolution was obtained by exposing $\mathrm{X}$-ray film to dried gels. For this purpose the sliced gels were transferred singly onto pieces of parafilm and frozen at $-20^{\circ}$. The frozen gels were then mounted between pieces of wire screen ( $5 / 16$-inch mesh), transferred to Pyrex vacuum desiccator jars, and lyophilized. Warping of the dried gels, which was occasionally encountered, could be eliminated by placing them between glass plates and gradually applying weight.

Preparation of autoradiographs. The $\mathrm{S}^{35}$ containing bands in the gels could be visualized by autoradiography. In the darkroom, $4 \times 10$-inch pieces of Kodak Royal Blue $\mathrm{X}$-ray film were mounted on $1 / 8$-inch masonite boards $(4 \times 11$ inches), small pieces of tape being applied on either end. The dried gels were then sandwiched between two such mounted films. A steel plate $(4 \times 11 \times 1 / 4$ inches) was placed on the outside of each of the masonite boards, and the entire array was then wrapped generously in heavy duty 18-inch width aluminum foil. These autoradiograph preparations were grouped between 1/4-inch plywood boards of appropriate size and clamped with large $\mathrm{C}$ clamps to assure close contact between gel and film. Exposure of the X-ray films varied between 1 and 7 days depending upon the extent of uptake of $\mathrm{S}^{35}$ in the particular experiment.

Exposed X-ray film was removed in the darkroom using a red safelight (Kodak Wratten Series 2). It was developed in Kodak D8 (68, 1.5 minute), transferred to Kodak indicator stop-bath for 30 seconds, 
rinsed in water for 30 seconds, fixed in Rapid Fixol (FR Corporation) for 4 minutes, and finally washed for 10 minutes.

A rapid assay for the $S^{35}$-labeled protein bands on a gel could be accomplished by pressing Whatman no. 1 ehromatography paper against the cut surface of the gel for 15 seconds, then rapidly drying the paper and placing it between X-ray films as described. While having the advantage of speed, this method does not give the fine resolution of the procedure outlined above.

\section{RESULTS}

\section{Proteins Synthesized during Infections Lead- ing to Phage Production}

Infections with mutant phages $c_{1}$ and $c_{2}$, both of which cause lysis rather than lysogeny, yielded similar results. Figure 1 shows a typical autoradiograph pattern of lysates of cells infected with phage $c_{2}$ and pulselabeled with $\mathrm{S}^{35}$ for 3 minutes at $1,5,10,15$, and 20 minutes after the onset of the infec tion. Little labeling occurred during the first ( 1 to 4 minute) pulse, as judged by the virtual absence of banding on the X-ray film. Distinct banding appeared as a consequence of the 5 to 8 minute pulse. The number of bands was fewer than that obtained from supernatants of extracts made from pulselabeled, uninfected cells. Despite the de- crease in number, some of the bands were clearly specific to the bacteria, since they were characteristically seen on autoradiographs of uninfected cells. Of special interest was the appearance of at least four new bands (Fig. 1, bands $A, B, C$, and $D$ ) not observed in uninfected bacteria. These bands first appeared during the 5 to 8 minute pulse and continued to be produced throughout the latent period, and in fact, until lysis. As mentioned above, phage $c_{1}$ infected rells gave a banding pattern similar to that of phage $c_{2}$.

\section{Proteins Synthesized during Infections leading to Lysogeny}

Banding patterns for cells infected with phage $c^{+}$pulse-labeled with $\mathrm{S}^{35}$ for 3 minutes at $1,5,10,15$, and 20 minutes after infection, are shown in Fig. 2. Some light banding appeared as a result of the 1 to 4 minute pulse. The 5 to 8 minute pulse produced a pattern similar to that already described for infections with phages $c_{1}$ and $c_{2}$. Again, some host-specific bands failed to appear. Bands A, B, C, and D, the bands not found in uninfected cells, were easily discernible in material pulsed from 5 to 8 minutes. Subsequent pulses, however, gave patterns of banding which deviated from those observed in infections leading to lysis. After the 5 to $\$$ minute

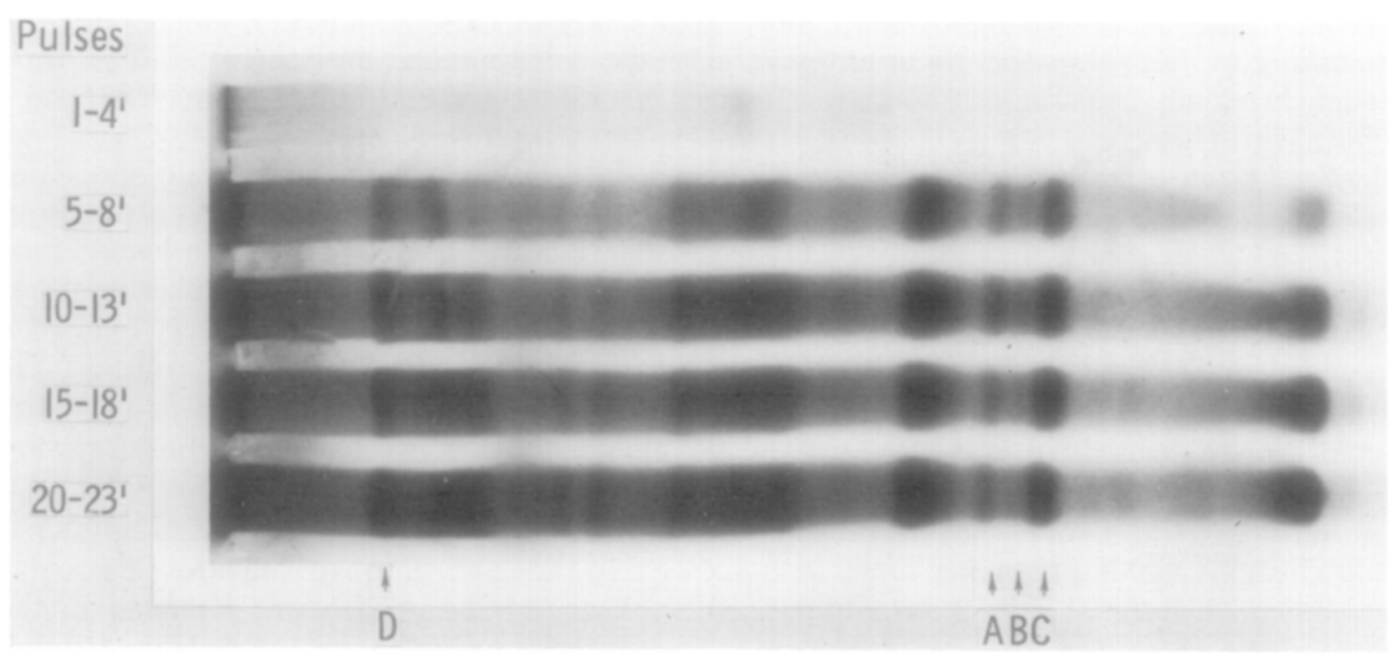

FIG. 1. An autoradiogram produced after starch gel electrophoresis of extracts of cells infected with phage $c_{2}$ and pulse-labeled with $\mathrm{S}^{35}$ for 3 minutes at $1,5,10,15$, and 20 minutes after the onset of infection. 
pulse, bands A, B, C, and D were less heavily labeled and were hardly detectable after the pulse from 15 to 18 minutes. Other bands present during the 5 to 8 minute pulse continued to be produced. In addition, bands characteristic of uninfected cells reappeared in later pulses (Fig. 2, pulses at 10 to 13,15 to 18 , and 20 to 23 minutes). It may be concluded that cells which survived infections and became lysogenic with phage $c^{+}$went through a transient stage characteristic of rells which lysed upon infection by $c$ mu1ants.
Of interest was the fate of bands A, B, C, and $\mathrm{D}$ after they were no longer produced. This was determined by a chase experiment. Cells infected with phage $c^{+}$were pulse labeled with $\mathrm{S}^{35}$ from 5 to 8 minutes, washed free of isotope, and resuspended in LSM for continued incubation. At various times, 20 -ml aliquots were removed and the cell extracts were examined for the presence or absence of the four bands. The bands could easily be detected 40 minutes after the onset of the infection, but began to disappear by

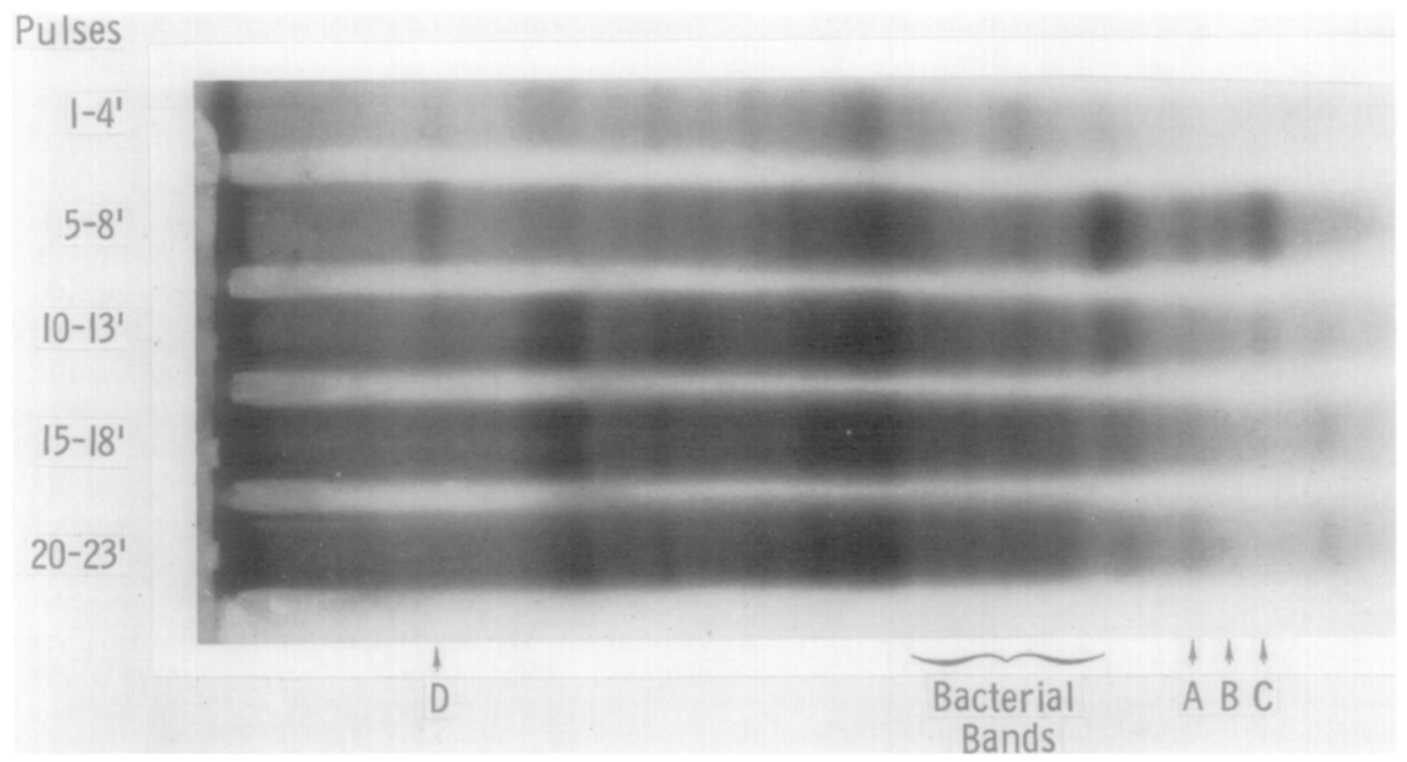

Fig. 2. An autoradiogram produced after starch gel electrophoresis of extracts of cells infected with phage $c^{+}$and pulse-labeled with $s^{35}$ for 3 minutes at $1,5,10,15$, and 20 minutes after the onset of infection.

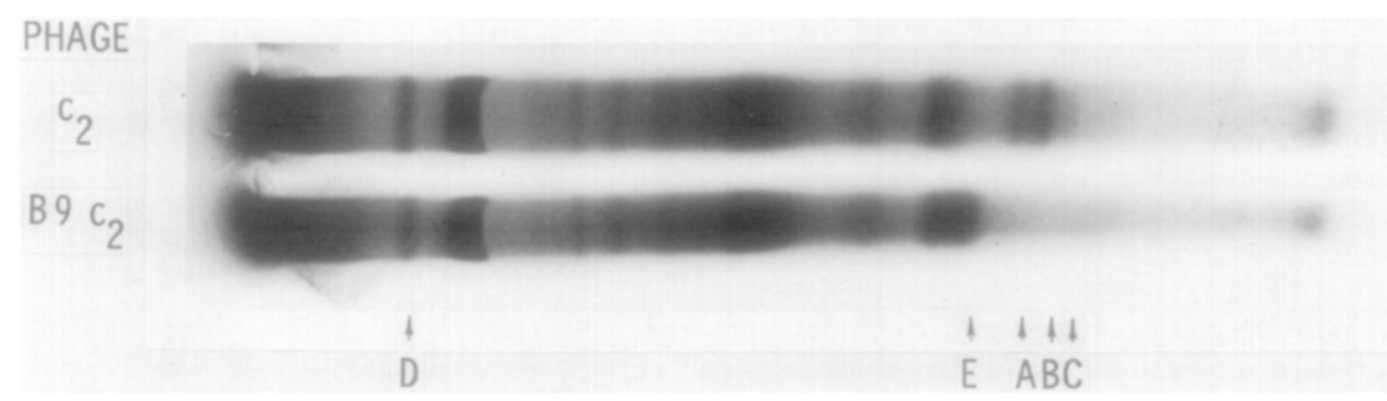

FIG. 3. An autoradiogram produced after starch gel electrophoresis comparing extracts of cells infected with phages $B 9 c_{2}$ and $c_{2}$ and pulse-labeled with $s^{35}$ at $37^{\circ}$ from 10 to 13 minutes after the onset of infection. 
50 minutes, when the growth rate of infected cells approached that of uninfected controls.

\section{Proteins Synthesized during Infections with Temperature-Sensitive Mutants}

Infections were carried out with $c_{2}$ derivalives of each of five complementing temperature-sensitive mutants at $37^{\circ}$ under the conditions previously described. These infections do not produce large bursts of phage at $37^{\circ}$, but synthesize normal numbers of progeny a.t $25^{\circ}$. The infected complexes were pulse-labeled with $\mathrm{S}^{35}$ from 10 to 13 minutes and the cell lysates were examined for variations in the $c_{2}$ banding pattern. Typical $c_{2}$ banding was observed with four of the five temperature-sensitive mutants. A strikingly altered banding pattern was seen with the fifth, mutant B9 (Fig. 3). Bands A, B, and C were not synthesized in infections with B9 $c_{2}$. However a new band, band $\mathrm{E}$, was detected.

\section{DISCUSSION}

The technique described in this paper may, in principle, be used to detect any sulfur-containing compound. Its primary utility in phage studies lies in the detection of sulfur-containing proteins. That the bands described in this paper, in particular bands $A, B, C$ and D, are proteins, is supported by staining with Amido-Schwartz, a specific protein stain. Additional bands might be detected using other labels. For the purposes of discussion it is assumed that the observed $\mathrm{S}^{35}$-labeled bands are indeed proteins.

Proteins A, B, C, and D are probably specified by phage genes. The four proteins are found only after infection. More important, the time-sequence of their synthesis during the course of infection is dependent upon the genotype of the phage used. In all three infections synthesis starts at the same time, about the 4th minute. When virulent mutants $c_{1}$ or $c_{2}$ are used, synthesis of bands $\mathrm{A}, \mathrm{B}, \mathrm{C}$, and $\mathrm{D}$ persists throughout the latent period, whereas in infections with wild-type $c^{+}$phage it continues through the 8 th minute and then ceases. Finally, the absence of bands $\mathrm{A}, \mathrm{B}$, and $\mathrm{C}$ in infections with mulant B9 and the simultaneous appearance of a new band, band $\mathrm{F}$, makes it unlikely that these are other than phage-determined proteins.

The pattern of synthesis of proteins A, B, $C$, and D correlates well with the pattern of synthesis of phage-specific DNA in $c^{+}$-infected complexes (Smith and Levine, 1964, 1965), justifying the speculation that these proteins may be early enzymes necessary for phage DNA synthesis. Other data suggest, however, that proteins $\mathrm{A}, \mathrm{B}$, and $\mathrm{C}$ may not be so involved. Cells infected with mutant phage B9 do not show bands $\mathrm{A}, \mathrm{B}$, and $\mathrm{C}$, but make normal amounts of DNA at $37^{\circ}$. Yet, these infections produce few active phage. Temperature-shift experiments demonstrate that the time of action of the B9 function is toward the end of the latent period, after large amounts of DNA have been produced (Levine, unpublished). Lysates from such infections contain serumblocking power, which does not sediment under conditions which sediment active phage (Israel, unpublished). These findings suggest that the B9 mutation affects some late step in the formation of phage particles.

There is no evidence regarding the role of protein $D$. In this connection it should be mentioned that in infections with a second temperature-sensitive mutant very little DNA is made at $37^{\circ}$, but all four bands are produced. We are cirrently attempting to isolate and characterize proteins $\mathrm{A}, \mathrm{B}, \mathrm{C}$, and D. Additional bands might be detected by varying the conditions for electrophoresis or by preliminary fractionation of the extracts.

Synthesis of proteins A, B, and C is initiated within the first few minutes of infection, at about the same time that phage DNA synthesis commences. Yet, these proteins appear to be involved in a late phage function. This suggests that phage loci involved in late functions come to carly expression. This has special significance for lysogeny. Not only is phage DNA synthesis regulated in cells destined to survive infection with temperate phage (Smith and Levine, 1964, 1965; Levine and Smith, 1964), but the synthesis of proteins associated with production of structural components of the phage is also shut off. The establishment of lysogeny appears to invoke active repression of synthesis associated with both early and late functions. 
It is of interest to consider whether the observed repressions of the syntheses of DNA and the four protein bands are under common control. In wild-type infections, phage DNA synthesis starts at about 4 minutes, reaches a peak 2-4 minutes later, and then the rate of synthesis begins to decrease until complete repression is achieved at 16 minutes (Smith and Levine, 1965). Control of phage DNA synthesis leading to lysogeny requires the action of two phage loci (Smith and Levine, 1964; Levine and Smith, 1964). The first, the $c_{1}{ }^{+}$locus, is responsible for initiating the repression, acting for only a 4-minute interval between the 7 th and 11 th minute. The $c_{2}{ }^{+}$locus begins to function at the 16 th minute, maintaining the repression on phagespecific DNA synthesis as the cells survive and become lysogenic. Failure of either of these repressions, as seen in $c_{1}$ and $c_{2} \mathrm{mu}$ tants, results in uncontrolled phage DNA synthesis, phage formation, and lysis of the colls. The synthesis of the protein bands would be expected to mimic DNA synthesis in $c^{+}, c_{1}$, and $c_{2}$ infections if both were under the control of the $c$ loci. This expectation is realized in $c^{+}$-infected complexes (the similar patterns of synthesis of phage DNA and bands $\mathrm{A}, \mathrm{B}, \mathrm{C}$ and $\mathrm{D}$ have already been commented upon) and in $c_{1}$-infected cells (the proteins are made throughout the latent period, as is DNA). A divergence of patterns occurs in $c_{2}$-infected cells. IIere, once the synthesis of the four bands begins, it continues throughout the infection without any sign of a period of repression as is observed for DNA synthesis. Since $c_{2}$ mutants have a $c_{1}^{+}$locus, it can be concluded that the $c_{1}{ }^{+}$ locus does not prevent the continued synthesis of bands $\mathrm{A}, \mathrm{B}, \mathrm{C}$ and $\mathrm{D}$. The fact that the $c_{2}{ }^{+}$locus does not act on DN $\Lambda$ synthesis until the 16th minute of the infection (Levine and Smith, 1964) tends to rule out a role for this gene in band repression. Repression of band synthesis is essentially complete by this time in wild-type infected cells. More conclusive is the absence of repression of band synthesis in infections with mutant $c_{1}$ where the $\mathrm{c}_{2}{ }^{+}$locus would be expected to express itself if it were involved in the control of band formation. The mechanism of control of band synthesis remains to be elucidated.
If neither the $c_{1}^{+}$nor $c_{2}{ }^{+}$loci are responsible, then additional controlling genes are implicated.

Accepting that bands $\mathrm{A}, \mathrm{B}$ and $\mathrm{C}$ are associated with late phage functions, questions arise as to their activity during various stages of infection. $\Lambda \mathrm{rc}$ these proteins active from the moment of their synthesis? Once synthesized in phage $c^{+}$-infected cells, these bands persist for at least 40 minutes. No active phage are produced. Are these proteins functional during this period? What is the mechanism responsible for the rapid loss of radioactivity from these bands after 40 minutes?

In mixed infection with mutants of the $c_{2}$ type, phages of the $c_{1}$ class lysogenize with high frequency (Levine, 1957). The complementation seen in mixed infections suggests that the observed repressions of DNA synthesis are mediated through cytoplasmic substances. However, synthesis of proteins which might represent these substances has not yet been detected.

Changes in the number of bands observed during phage $c^{+}$infections suggest that certain host-specific proteins go through a period of decreased synthesis and subsequent release, as was observed for bacterial DNA synthesis. The possibility that the control of these host syntheses resides in the phage genome is being explored.

\section{REFERENCES}

Levine, M. (1957). Mutations in the temperate phage P22 and lysogeny in Salmonella. Virology $3,22-41$.

Levine, M., and Curtiss, R. (1961). Genetic fine structure of the $\mathrm{C}$ region and the linkage map of phage P22. Genetics 46, 1573-1580.

Levine, M., and Smith, H. O. (1964). Sequential gene action in the establishment of lysogeny. Science 146, 1581-1582.

Smith, H. O., and Levrne, M. (1964). Two sequential repressions of DNA synthesis in the establishment of lysogeny by phage P22 and its mutants. Proc. Natl. Acad. Sci. U.S. 52, 356-363.

Smith, H. O., and Levine, M. (1965). The synthesis of phage and host DNA in the establishment of lysogeny. Virology 25, 585-590.

SMITHIES, O. (1959). An improved procedure for starch gel electrophoresis: further variations in the serum proteins of normal individuals. Bio chem. J. 71, 585-587. 